\title{
MARTIN BUBER: UMA ALTERNATIVA PARA SE PENSAR AS INTER- RELAÇÕES NO COTIDIANO ESCOLAR
}

ARRUDA, Márcia R. M.Ferraz

BADIA, Denis Domeneghetti ${ }^{1}$

\section{Resumo}

Nesta comunicação procuramos mostrar a propriedade das idéias de Martin Buber, na obra $\mathrm{Eu}$ e $\mathrm{Tu}$ (2001), para se pensar as inter-relações na escola. Em termos antropológicos, no cotidiano escolar se configuram, simultaneamente, cultura organizacional e a cultura de grupos, segundo Edgar Morin (1984) e Michel Maffesoli (1998). Buscamos na "filosofia do encontro" uma reflexão sobre as relações intersubjetivas produzidas pelos sujeitos no cotidiano escolar. São relações que efetivam a comunicação, definida por Buber como um encontro, no qual se dá a complementaridade e reciprocidade das ações entre o Eu-Tu, o dialógico, em detrimento à experiência de contato proporcionada no Eu-Isso, o monológico. A questão a ser iluminada diz respeito ao fato de que, por meio da "filosofia do encontro", talvez possamos encontrar suportes teóricos consistentes para repensarmos as relações produzidas pelos sujeitos no âmbito escolar, o que evidencia o caráter "ontológico" de uma questão crucial na escola: ensino-aprendizagem.

\footnotetext{
${ }^{1}$ Universidade Estadual Paulista, Faculdade de Ciências e Letras - FCL-CAr Centro Interdisciplinar de Pesquisas sobre o Imaginário - CIPI UNESP/CAr Araraquara - S.P - Brasil - $\underline{\text { mrferraz@ @clar.unesp.br }}$
} 


\section{Introdução}

Neste trabalho em desenvolvimento, utilizamos como referencial teórico os estudos antropológicos do Imaginário ${ }^{2}$ para mostrar a propriedade do entendimento da ‘filosofia do encontro', elaborada por Martin Buber (2001), a fim de se pensar as interrelações no cotidiano da escola, entendida aqui como instituição social - cultura organizacional - e também como organização afetual ${ }^{3}$ - cultura de grupos, segundo Edgar Morin (1984) e Michel Maffesoli (1998).

Buber nos apresenta uma reflexão acerca da comunicação entre os sujeitos, sugerindo-a como uma manifestação dialógica. É exatamente nesse ponto que pensamos a comunicação traduzindo as subjetividades daqueles que se inserem no cotidiano da escola. Esta, regida pelas teorias de administração e do planejamento, privilegia o modelo de organização burocrática, por meio de uma intervenção gestionária. Visa, portanto, à racionalização máxima das atividades segundo esquemas pré-estabelecidos e ainda segundo os meios para se atingir fins pré-determinados, não perdendo, mesmo assim, seu caráter simbólico. Considerada também como grupo social, há de se ressaltar que a mesma se estabelece a partir de organizações afetuais, ou seja, as que priorizam a vida afetiva do grupo, manifestadas no sistema de idéias, crenças, valores e sentimentos. A esse respeito, afirma-nos Paula Carvalho (1991) que considerá-las como sistemas simbólicos é aceitá-las como grupos reais e relacionais vivenciando códigos e sistemas de ação, correspondendo àqueles sistemas simbólicos as práticas simbólicas tidas como práticas sociais dos grupos.

\footnotetext{
${ }^{2} \mathrm{O}$ termo Imaginário é utilizado aqui a partir das proposições de Gilbert Durand, segundo o qual imaginário é o conjunto das imagens não gratuitas e das relações de imagens que constituem o capital inconsciente e pensado do ser humano. (COELHO, Teixeira. Dicionário crítico de política cultural. $3^{\text {a }}$ ed. São Paulo:Iluminuras, FAPESP, 2004, p.212).

${ }^{3}$ Maffesoli, Michel. Aux creux dês apparences (Pour une éthique de lésthétique). Paris: Plon, 1990.
} 


\section{Desenvolvimento}

Ao associarmos as reflexões de Buber ao cotidiano escolar encontramos o que nos parece ser uma decisiva contribuição para repensarmos/entendermos, no cenário contemporâneo, as relações que se cristalizam no interior daquele cotidiano.

O pensamento de Buber nos aponta a existência de uma 'filosofia do encontro’ que se apóia na complementaridade e reciprocidade das ações e das relações existenciais proporcionadas por uma comunicação, instaurada entre as consciências individuais e sociais. É o tecido relacional que se efetiva pelo encontro expresso entre Eu-Tu, o dialógico, em detrimento à experiência de contato proporcionada no Eu-Isso, o monológico. Buber nos leva à convicção de um olhar (perdido na contemporaneidade) sobre a intimidade do nosso interlocutor, numa dinâmica que acolha a zona de silêncio muitas vezes estabelecida em um diálogo, o que instaura a confiança no interlocutor. É no e a partir desse olhar que se encontram "[...] o calor e a gratuidade da resposta. Quem ouve se não é para responder?”, indaga-nos Buber. Afirma-nos, ao mesmo tempo, que nas inter-relações “[...] a semente do Tu já havia sido lançada: o lugar dos outros é indispensável para a nossa realização existencial." Essa afirmação nada mais é do que a efetivação das práticas simbólicas que se traduzem em respeito pelo outro.

O autor em questão nos aponta para uma postura a ser assumida nas interrelações com nosso interlocutor, a 'filosofia do encontro'. Essa 'filosofia do encontro' consiste, portanto, em uma relação eu-outro, na qual o poder do eu não viole a alteridade do outro, isto é, uma relação que se traduza na preservação absoluta do sujeito, o que inibirá uma iniciativa individualista do eu. Para Buber, a materialidade dessa preservação é o que constitui a 'filosofia do encontro'.

À propósito da comunicação realizada por meio de um diálogo em que a alteridade seja intocada, Buber afirma que esse tipo de comportamento possibilita o 
chamado diálogo de confronto. Todavia, fala-se de um confronto mediado por atitudes aceitáveis, configurando comportamentos de confronto e de respeito, simultaneamente. Em verdade, esse confronto é o meio pelo qual a alteridade é resguardada, uma vez que em cada tu um $e u$ específico se faz presente.

Ainda, segundo Buber, as atitudes manifestadas pelos sujeitos mediante as relações que estabelecem entre si se traduzem pela palavra-princípio Eu-Tu e pela palavra-princípio Eu-Isso. Enquanto a primeira é vista como um ato essencial do homem/ser, respeitando-se a alteridade, um encontro entre dois parceiros na reciprocidade, a segunda é a experiência e a utilização. Buber denomina esses princípios, respectivamente, de dialógico e monológico.

Importante ainda para entendermos a 'filosofia do encontro' de Buber é mencionarmos aqui que não há a existência de dois "Eus". O que se tem é a dupla possibilidade de existir como homem: dois mundos, dois sujeitos, portanto. Porém, podemos sempre estabelecer os dois tipos de relações: Eu-Tu e o Eu-Isso. O fundamental é que nas duas relações o Tu sempre seja assumido anterior ao Isso. Em verdade, para Buber, não há um Eu em si, mas apenas o Eu da palavra-princípio Eu-Tu e o Eu da relação Eu-Isso. A retomada, portanto, de um sujeito-objeto - que é separado de si mesmo e do mundo-, para se pensar um sujeito-sujeito é que configura a constituição da socialidade ${ }^{4}$ da relação Eu-Tu, caracterizando-se em relações dialógicas.

Faz-se necessária, neste momento, uma reflexão sobre o meio básico da efetivação das relações: a palavra. Segundo, Buber (Op. cit., p. 41) a primeira categoria da dialogicidade da palavra está no "entre" e é portadora do ser. Uma vez proferida, a palavra se torna efetivamente uma atitude capaz de atualizar o ser do homem, situandoo no mundo com os outros homens. Assim, ainda que existente apenas mediante uma

\footnotetext{
${ }^{4}$ Maffesoli, Michel. No tempo das tribos. São Paulo: Forense Universitária, 1987.
} 
intencionalidade, a palavra se caracteriza como o princípio ontológico do homem, elevando-o à categoria de ser dia logal e dia pessoal. Desse modo, a vida em diálogo, na perspectiva de Buber, aponta para a preservação da alteridade e homogeneidade absoluta do outro.

O fenômeno da relação é descrito por Buber (Op. cit., p. 47) com o emprego de vários termos: diálogo, relação essencial e encontro. A diferença que há entre relação essencial e encontro reside no fato de que o encontro é um evento presente ou atual e a relação essencial é um evento que engloba todos os novos encontros dialógicos. Para esse autor, o dialógico é a forma explicativa do fenômeno inter-humano, entendendo-se inter-humano como sendo um encontro mútuo que, ao mesmo tempo, denota presentificar e ser presentificado. A reciprocidade se constitui, então, como a característica definitiva da atualização do fenômeno da relação, considerando-se o "entre" como uma categoria ontológica. Assim, o "entre", o "inter-valo", caracteriza-se como o lugar no qual se revela a palavra proferida pelo ser, por um dos sujeitos da relação. É um intervalo existente entre o Eu e Tu e o Eu e Isso. As relações do Eu e Isso se fundam no inter e dia pessoal, enquanto as relações Eu e Tu se pautam em uma “[...] conivência ontológica para o conhecimento do mundo.", afirmação comprovada por Bachelard (apud BUBER, op. cit., p. 49) quando nos diz que as "[...] coisas infinitas como o céu, a floresta e a luz não encontram seu nome senão dentro de um coração amante." É o sentido da co-participação dia logal, a compreensão da participação do Eu-Tu que se harmonizam e configuram o dialógico a partir da noção de totalidade, que é entendida por Buber como uma relação independente, mesmo que essa independência não seja apenas relativa.

O entendimento de um Eu-Tu e Eu-Isso - como palavras-princípio que estabelecem modos de ser-no-mundo e atribuem uma “[...] diferença no estatuto 
ontológico do outro" -, é, pois, a condição primordial de existência das relações entre sujeitos, levando-se em conta o princípio da alteridade já mencionado. Importante ainda explicitar que, segundo Buber (Op. cit., p. 49) o meu Eu, ou seja, o Eu da relação Eu-Tu se deve ao fato de dizer Tu ao interlocutor da relação, portanto o Eu dessa relação.

Desse modo, chegamos ao princípio da totalidade precedendo a separação e, conseqüentemente, a palavra princípio Eu-Tu precedendo a palavra Eu-Isso. Este tem o 'Eu' utilizando a palavra para conhecer um mundo que assume a forma de objeto de uso e experiência, impor-se a ele, transformando-o. Em contrapartida, o Eu-Tu é contemplação e totalidade, momento em que os "Eus" da relação apreendem a realidade, apesar das diferenças nos pólos das relações com o Tu ou com o Isso. Tem-se a ocorrência do Mitdaisen, ou seja, o coexistir das palavras-princípio, ou o que Buber (Op. cit., p. 53) nomeia de "[...] reino dos verbos transitivos. Ele é essencial na vida humana, mas não pode ser o sustentáculo ontológico do inter-humano." Ainda na visão desse autor, não há nenhuma circunstância negativa ou inferior na palavra-princípio EuIsso. O que ele defende são as atitudes assumidas frente ao mundo no qual o sujeito está inserido. Essas podem submetê-lo à fatalidade e à destruição de si mesmo quando o EuIsso assumir uma relação de não-ética, voltando propósitos e interesses à sua própria existência, desconsiderando-se a sistemática que precede essa relação. A esse respeito, Buber (Op. cit.; p. 54) afirma-nos que “[...] o homem não pode viver sem o Isso...E mais, está maravilhosamente voltado a constituir um sistema e uma estrutura de idéias que constituam seu refúgio frente à agressão do nada. No entanto, quem somente vive no Isso não é homem".

Mediante a aceitação de que o Eu não se traduz numa "realidade em si", mas em algo relacional, para Buber (Op. cit.; p. 55) o Eu é livre para se decidir por uma ou por outra atitude, revelando o fenômeno da relação Homem-Mundo. Tem-se uma 
relação estabelecida no momento em que o Tu se oferece a um encontro e por sua própria decisão o Eu vai encontrá-lo. Contrariamente a uma postura cientificista do homem moderno que se reconhece apenas na palavra princípio Eu-Isso, entendendo-se o Isso como objeto, temos a "fillosofia do outro" que prevê a "[...] irredutibilidade do Tu a um objeto. Em hipótese nenhuma o outro pode ser submetido à categoria objeto.”, sob pena de se definir neste ponto o destino do homem. Assim, “[...] torno-me Eu na relação com o Tu', tendo em vista que o 'Eu age sobre o Tu e o Tu, sobre o Eu', concretizando uma relação pautada na realização e efetivação de uma vida dialógica.

Inserir, portanto, o dialógico nos sujeitos se traduz numa abordagem antropológica fundamental e necessária para o entendimento das suas múltiplas interrelações ou, retomando Buber, quando nos afirma que o 'entre' que nos é indicado assumirá função primordial em nossas vidas, pois revelará nossa totalidade enquanto sujeitos e rejeitará a racionalidade como característica única para uma suposta vida 'dialógica'. Em sentido oposto, o que se espera é a relação dialógica embasada na presentificação das palavras-princípio Eu-Tu, entendendo que “[...] no encontro dialógico acontece uma recíproca presentificação do Eu e do Tu. A alteridade essencial se instaura somente na relação $\mathrm{Eu}-\mathrm{Tu}$; no relacionamento Eu-Isso o outro não é encontrado como outro em sua alteridade". (BUBER, op. cit.; p. 56).

É na necessidade ontológica de receber uma palavra e respondê-la que se insere a característica principal do "entre". Tem-se, então, o chamado "fenômeno da responsabilidade' em seus dois sentidos, ou seja, num primeiro momento a resposta e, num segundo momento, a necessidade, obrigação de responder. É a caracterização do homem enquanto responsável por viver plenamente o real e essencial nas inter-relações. Erroneamente, porém, o projeto da modernidade traduz as inter-relações como algo $a$ posteriori em relação à execução dos fatos, considerando a relação Eu-Tu um porto de 
chegada para a travessia realizada pela experiência Eu-Isso, uma pragmática que não só contraria o pensamento do autor em questão, mas evidencia as relações no cotidiano escolar.

Num contexto em que a exigência de um sujeito 'moldado' a partir de um cientificismo não mais se sustenta, reiterarmos a necessidade de uma reflexão sobre os relacionamentos vivenciados naquele cotidiano escolar, considerando-se a atitude Eu-Tu, o encontro e a inter-relação, tendo em vista as subjetividades dos sujeitos envolvidos no processo educativo. Por meio da 'filosofia do encontro' questionamos as possíveis inter-relações no cotidiano escolar, tendo em vista que os processos relacionais que emergem daquele espaço, em todas as instâncias, são dependentes das limitações e restrições com relação à existência do outro. Uma possível solução para se repensar as relações entre os sujeitos, segundo Buber (Op. cit., p. 150), talvez esteja no 'fenômeno da resposta' e num retorno do que mais caracteriza o homem: sua humanidade.

\section{Conclusão}

É indiscutível o fato de que inúmeras são as lacunas quanto à efetivação do "entre com" ou do "estar-junto-com", porque algumas relações, pelas especificidades próprias, não podem concretizar a mutualidade plena desejada e um exemplo desse fato é a relação estabelecida entre os sujeitos educativos inseridos no cotidiano: o professor apreende o aluno como um sujeito inserido numa totalidade, bem como as interações que tentam estabelecer. Porém, por meio das reflexões já expostas não nos pautamos em constatações ou em críticas, ao contrário, a idéia é de nos posicionarmos por caminhos que nos reconduzam a concepções de uma educação mais totalizante ou, conforme nos orienta Paula Carvalho (1991), há de se preconizar e valorizar um conceito ampliado de 
educação, assumindo-se um "teor educativo pervagante" (grifo do autor), ou seja, que transpasse pelas práticas simbólicas de modo que essas organizem processos simbólicoorganizacionais cujo teor educativo não se reduza meramente à instrução, ao ensino ou à chamada "praxeologia", mas privilegie a pluralidade e a complementaridade necessárias às dinâmicas educativas.

Mediante o exposto, evidencia-se a pertinência das idéias de Buber para se pensar as relações estabelecidas no cotidiano escolar, tendo em vista a preservação da alteridade dos sujeitos envolvidos: professor-aluno, aluno-professor, aluno-aluno. Acreditamos que se essas relações ocorressem dialogicamente, poderíamos dizer, parece-nos, que haveria mais sucesso do processo ensino-aprendizagem, uma vez que a alteridade do $t u$ não seria transposta pelo $e u$. Trata-se, portanto, de um procedimento diretamente relacionado à quebra de preconceitos e à quebra do 'tipo ideal', ligado, necessariamente, à necessidade de um reencantamento de mundo por meio de novas formas de relações sociais.

\footnotetext{
${ }^{5}$ A expressão ‘tipo ideal' aqui é utilizada apenas para denominar aquilo que poderíamos chamar do desejado pelo Eu e que não preserva a alteridade.
} 


\section{Referências bibliográficas}

Buber, M. (2001). Eu e tu. São Paulo: Centauro.

Coelho, T. (2004). Dicionário crítico de política cultural. São Paulo: Iluminuras.

Durand, G. (1993). Les structures anthropologiques de l'imaginaire: introduction à l'archétypologie générale. Paris: Dunod.

Maffesoli, M. (1985). A conquista do presente. Rio de Janeiro: Rocco.

Maffesoli, M. (1998). Elogio da razão sensível. Petrópolis: Vozes.

Morin, E. (1984). Sociologie. Paris: Fayard.

Paula Carvalho, J. C. (1991). A culturanálise de grupos: posições teóricas e heurísticas em educação fática e ação cultural. Universidade de São Paulo, São Paulo. (Mimeo). 
